\title{
Papers
}

\section{Income inequality, individual income, and mortality in Danish adults: analysis of pooled data from two cohort studies}

\author{
Merete Osler, Eva Prescott, Morten Grønbæk, Ulla Christensen, Pernille Due, Gerda Engholm
}

\begin{abstract}
Objective To analyse the association between area income inequality and mortality after adjustment for individual income and other established risk factors. Design Analysis of pooled data from two cohort studies. The relation between income inequality in small areas of residence (parishes) and individual mortality was examined with Cox proportional hazard analyses.

Setting Two population studies conducted in Copenhagen, Denmark.

Participants 13710 women and 12018 men followed for a mean of 12.8 years.

Main outcome measure All cause mortality.

Results Age standardised mortality was highest in the parishes with the least equal income distribution. After adjustment for individual risk factors, parish income inequality was not associated with mortality, whereas individual household income was. Thus, individuals in the highest income quarter had lower mortality than those in the lowest quarter (adjusted hazard ratio for men 0.51 (95\% confidence interval 0.45 to 0.59 ) and for women 0.60 (0.54 to 0.68$)$ ).

Conclusion Area income inequality is not in itself associated with all cause mortality in this Danish population. Adjustment for individual risk factors makes the apparent effect disappear. This may be the result of Denmark's welfare system, based on a Nordic model.
\end{abstract}

\section{Introduction}

The idea that income inequality may be associated with health and mortality has attracted considerable research interest. ${ }^{1-3}$ Several ecological studies using different income distribution measures have shown that higher levels of inequality in income among states ${ }^{4-7}$ or cities $^{89}$ in the United States are associated with higher all cause mortality, whereas in Canadian states and cities income inequalities are smaller and not associated with mortality. ${ }^{9}$ In a few cross sectional studies, income inequality at state or county level in the United States has also been associated with coronary risk factors ${ }^{10}$ and poor self rated health after adjustment for individual socioeconomic status and income. ${ }^{11}{ }^{12}$ It has therefore been suggested that areas with an unequal income distribution are less likely to invest in health and more likely to have a psychosocial climate that is damaging to health. ${ }^{13}$

Only a few prospective studies, all from the United States, have examined whether area income inequality is related to individual health outcomes. Fiscella and Franks found that income inequality at community level did not predict all cause mortality after control for individual income, ${ }^{14}$ whereas other studies have suggested an effect in different subpopulations. ${ }^{15-17}$ These relations are likely to differ among other Western countries too, but to our knowledge no studies have examined whether area based measures of income inequality predict all cause mortality after adjustment for individual income and other risk factors in a society outside the United States.

We analysed whether income inequality at the parish level predicted increased mortality after adjustment for individual income and standard risk factors in a society built on the Nordic welfare model.

\section{Methods \\ Participants}

The study is based on data from two longitudinal population studies conducted in Copenhagen. The Copenhagen city heart study comprised 14223 randomly selected men and women aged 20 years or more from a defined area of central Copenhagen in $1976-8^{18}$; in $1981-3$ and $1993-4$ the participants were re-examined and 3816 new participants were included. The Glostrup population study examined and followed, between 1964 and 1992, 10092 participants from different birth cohorts (born during 1897-1962) in selected western suburbs of Copenhagen. ${ }^{19}$ Both studies were approved by the relevant scientific and ethics committees. Of 35977 adults originally invited to join these two studies, 7846 had not taken part (response rate 78\%). Our study is therefore based on a combined population of 28131 adults (14723 women).

We obtained information on housing, income, occupation, and education from Danish registers (see below) for 25728 participants (13 710 women) and 5927 non-participants. For 2403 (8.5\%) participants and 1919 (24.5\%) non-participants this information was missing because they had died before 1980 or had

\author{
Department of \\ Social Medicine, \\ Copenhagen \\ Center of \\ Prospective \\ Population Studies, \\ Institute of Public \\ Health, University \\ of Copenhagen, \\ Blegdamsvej 3 , \\ 2200 N, Denmark \\ Merete Osler \\ professor \\ Ulla Christensen \\ assistant professor \\ Pernille Due \\ associate professor \\ Copenhagen \\ Center of \\ Prospective \\ Population Studies, \\ Danish \\ Epidemiology \\ Science Centre at \\ the Institute of \\ Preventive \\ Medicine, \\ Copenhagen \\ University Hospital, \\ 1399 Copenhagen, \\ Denmark \\ Morten Grønbæk \\ senior research fellow \\ Eva Prescott \\ senior research fellow \\ Centre for Research \\ in Health and \\ Social Statistics, \\ 2100 Copenhagen, \\ Denmark \\ Gerda Engholm \\ senior research fellow \\ Correspondence to: \\ M Osler \\ M.Osler@socmed. \\ ku.dk
}

BMJ 2002;324:1-4 
moved out of the metropolitan area. The mean household gross income was $£ 29650$ (SD £24 700) for participants and $£ 22400$ ( $£ 20$ 260) for non-participants. Analyses of the relation between registers' data and mortality showed the same direction of associations when data were analysed for participants and non-participants separately. Thus our analyses are based on the 25728 participants with complete data.

\section{Data collection}

We linked the study population to registers with socioeconomic information held by the organisation Statistics Denmark ${ }^{20}$ using the "person identification number." We obtained information on housing, income, occupation, and education for participants and their cohabiting partners (married or nonmarried) for the years 1980, 1985, 1990, and 1995. We used data from the year nearest to the baseline examination. We obtained area based information by aggregating individual information for each year for the whole population (about 1.1 million) in the study area at parish level. The 153 parishes had a mean of 7500 (range 600-17 400) inhabitants in 1990; a mean of 168 (range 5-2128) of the study population lived in 149 of the parishes.

\begin{abstract}
Measures of individual income
Every inhabitant in Denmark aged more than 15 years is classified annually according to income and wealth in the register of income statistics. For each participant and cohabiting partner we obtained information on gross income and calculated the household income as the sum of the individual's and his or her cohabitant's gross income. The gross income comprises all income types subject to income taxation (wages and salaries, all types of benefits and pensions, net surplus or deficit, interest received, and shared dividends). ${ }^{21}$ We corrected income for inflation since 1985 using the price index in the Statistics Denmark register. They are expressed in
\end{abstract}

Table 1 Individual baseline and area information for 25728 men and women, according to degree of income inequality in 149 parishes in metropolitan area of Copenhagen

\begin{tabular}{|c|c|c|c|c|}
\hline \multirow[b]{2}{*}{ Variable } & \multicolumn{4}{|c|}{ Median share of income* } \\
\hline & $\begin{array}{l}\text { Lowest quarter } \\
\text { (least equality) }\end{array}$ & $\begin{array}{l}\text { Second } \\
\text { quarter }\end{array}$ & $\begin{array}{l}\text { Third } \\
\text { quarter }\end{array}$ & $\begin{array}{l}\text { Highest quarter } \\
\text { (most equality) }\end{array}$ \\
\hline No of participants & 6588 & 6712 & 6295 & 6133 \\
\hline \multicolumn{5}{|l|}{ Area level: } \\
\hline Mean household income (£) & 25440 & 23064 & 24571 & 33380 \\
\hline No $(\%)$ of households with children & $1304(19.8)$ & $1376(20.5)$ & $1882(29.9)$ & $2840(46.3)$ \\
\hline \multicolumn{5}{|l|}{ Individual level: } \\
\hline No $(\%)$ of men & $2879(43.7)$ & $3020(45.0)$ & $3418(54.3)$ & $3398(55.4)$ \\
\hline Mean age (years) & 52.6 & 52.3 & 49.1 & 46.1 \\
\hline $\begin{array}{l}\text { No (\%) of participants with } \\
<8 \text { years' schooling }\end{array}$ & $3123(47.4)$ & $3141(46.8)$ & $2789(44.3)$ & $2373(38.7)$ \\
\hline Mean household income (£) & 26450 & 26827 & 30495 & 35292 \\
\hline No (\%) of households with children & $1061(16.1)$ & 1255 (18.7) & $1794(28.5)$ & $2607(42.5)$ \\
\hline No $(\%)$ of smokers & $4006(60.8)$ & $4229(63.0)$ & $3758(59.7)$ & $3428(55.9)$ \\
\hline No $(\%)$ of sedentary participants & $1351(20.5)$ & $1329(19.8)$ & $1435(22.8)$ & $1607(26.2)$ \\
\hline $\begin{array}{l}\text { No }(\%) \text { of participants in highest } \\
\text { category for alcohol consumption }\end{array}$ & $863(13.1)$ & $973(14.5)$ & $812(12.9)$ & 705 (11.5) \\
\hline Mean body mass index $\left(\mathrm{kg} / \mathrm{m}^{2}\right)$ & 25.0 & 25.2 & 25.0 & 24.9 \\
\hline $\begin{array}{l}\text { All cause mortality (per } 1000 \\
\text { person years) } \dagger\end{array}$ & 28.4 & 28.2 & 23.4 & 17.5 \\
\hline \multicolumn{5}{|c|}{$\begin{array}{l}\chi^{2} \text { test }(\%) \text {, Kruskal-Wallis (mean), or Mantel-Cox score tests for trend of rates for differences between } \\
\text { quarters: all tests were significant }(\mathrm{P}<0.05) \text {. } \\
\text { *Lowest quarter, 13.9-21.9\%; second quarter, 22.0-22.7\%; third quarter, 22.8-24.2\%; highest quarter, } \\
24.3-30.3 \% \text {. } \\
\text { †Follow up until } 2000 .\end{array}$} \\
\hline
\end{tabular}

1995 prices, and a conversion rate of Kr10 to £1 was used.

Measures of income inequality in area of residence We used the median share of income in each parish estimated as the proportion of total household gross income earned by the poorer $50 \%$ of the households in the area, ${ }^{814}$ calculated for the total population. The mean median share of income within the parishes was 22.7\% (median 22.8\%; range 13.9-30.3\%).

\section{Other covariates}

Information on type of household at individual level (four categories: one or two cohabiting adults, with or without children aged $<18$ years) and area level (proportion of cohabiting partners with children aged $<18$ years in an area) was derived from registers in Statistics Denmark.

Standard risk factors were assessed for each participant at baseline by a self administered questionnaire and a health examination. We calculated body mass index as weight $(\mathrm{kg}) /\left(\right.$ height $\left.(\mathrm{m})^{2}\right)$. We categorised participants as non-smokers (never or former smokers) and smokers and classified alcohol consumption according to average daily intake ( $<1$ drink, 1-2.9 drinks, 3-5.9 drinks, 6-10.9 drinks, $\geqslant 11$ drinks); one drink contained 9-13 g alcohol. We categorised physical activity in leisure time as sedentary $(<4$ hours of activity a week) or active ( $>4$ hours a week). We categorised educational level according to years of schooling ( $<8$ years (completed primary school); 8-11 years; and $>11$ years $)$.

\section{Follow up}

Participants were followed from 1980 until 31 October 1999 for total mortality in the national central person register (mean follow up 12.8 years).

\section{Statistical methods}

Associations between risk factors and mortality was analysed by using Cox's proportional hazards regression models, with age as the underlying time scale and accordingly using a model for delayed entry (left censoring). ${ }^{22}$ The continuous variables were evaluated for linearity. Categorisation giving the best model fit was chosen. The proportional hazards assumption was evaluated for all variables by comparing estimated $\log$-log survivor curves over the different categories of the variables being investigated and by tests based on the generalisation of Grambsch and Therneau. ${ }^{23}$ Because the number of participants in each area varied and those belonging to the same area were more likely to be alike, data were analysed by using a robust estimator of variance. ${ }^{24}$ The likelihood ratio test was used to test for interaction between income inequality and income of individuals. Statistical analyses were performed with STATA for Unix version 6.

\section{Results}

Compared with participants living in parishes with a more unequal income distribution, those in parishes with the most homogeneous income distributionnamely, the highest quarter-had higher income levels both at individual and area level; were younger; had a higher proportion of men and of cohabiting partners with children (both at individual and area level); and had 
Table 2 Adjusted mortality per 1000 person years in relation to area median share of income and household income at individual level

\begin{tabular}{|c|c|c|c|c|c|}
\hline \multirow[b]{2}{*}{ Household income at individual level } & \multicolumn{4}{|c|}{ Median share of income } & \multirow[b]{2}{*}{$\begin{array}{c}\text { Rate ratio (95\% } \\
\text { confidence interval)* }\end{array}$} \\
\hline & $\begin{array}{l}\text { Lowest quarter (least } \\
\text { equality) }(n=6588)\end{array}$ & $\begin{array}{l}\text { Second quarter } \\
\quad(n=6712)\end{array}$ & $\begin{array}{l}\text { Third quarter } \\
(n=6295)\end{array}$ & $\begin{array}{l}\text { Highest quarter (most } \\
\text { equality) }(n=6133)\end{array}$ & \\
\hline Lowest quarter & 34.5 & 36.0 & 35.1 & 31.0 & 1.00 (0.97 to 1.04$)$ \\
\hline Second quarter & 33.2 & 27.7 & 27.3 & 24.1 & $0.96(0.91$ to 1.00$)$ \\
\hline Third quarter & 24.0 & 25.5 & 18.9 & 16.1 & $1.02(0.97$ to 1.07$)$ \\
\hline Highest quarter & 21.0 & 23.3 & 14.9 & 11.8 & 1.00 (0.94 to 1.07) \\
\hline Rate ratio (95\% confidence interval)† & $0.83(0.80$ to 0.87$)$ & $0.83(0.79$ to 0.86$)$ & $0.81(0.77$ to 0.85$)$ & $0.82(0.77$ to 0.88$)$ & \\
\hline
\end{tabular}

${ }^{*}$ Mantel-Cox score test for trend in mortality across quarters with decreasing inequality, controlling for age and sex.

†Mantel-Cox score test for trend in mortality across quarters with increasing income, controlling for age and sex.

lower proportions of smokers, people with sedentary leisure time, and people with less education (table 1).

In total, 3460 women and 4107 men died during follow up, and age standardised mortality was highest in the parishes with the least homogeneous income distribution. Mortality among the participants in the lowest quarter of household income was significantly higher than among those in the highest income quarter. This ratio was not modified by the level of income inequality of the area (table 2). In the Cox regression analyses, area income inequality was not associated with mortality in women before or after adjustment for other risk factors (table 3). Men in the areas with most equality had lower mortality than those from areas with least equality, but the relation vanished when individual income or other risk factors were included in the model. In both men and women those with highest level of income had lowest mortality. Area income inequality did not predict mortality in any quarter of individual income.

\section{Discussion}

This study showed no association between income inequality at parish level and all cause mortality either in women or (after adjustment for individual income or other risk factors) in men, but it confirmed the well established inverse relation between individual income and mortality.

To compare our findings with previous studies we used gross income (including pensions and benefits)- that is, income before taxation. As the Danish taxation system aims at levelling out extreme incomes, gross income indicates a wider income disparity than actually exists, but since the ranking of areas is not influenced this is unlikely to affect the risk estimates. The rates of inequality in the parishes in Copenhagen city were similar to those reported from US communities $^{14}$ and cities, ${ }^{8}$ and in accordance with most ecological studies we found that areas with least equality had highest mortality at the aggregate level. Our study also supports Fiscella and Franks's finding that area income inequality is not in itself associated with all cause mortality, ${ }^{14}$ as adjustment for individual income made the apparent effect disappear. Contrary to three other prospective studies, ${ }^{15-17}$ we found no relation between area income inequality and mortality in any subgroups defined by sex, age, or income. One of the concerns about Fiscella and Franks's finding is that they used a level of aggregation that was too small to allow income distribution to exert an effect independent of individual income. ${ }^{12}$ It has been suggested that the level of geographical aggregation influences the pathways through which income inequality affects individual morbidity risk. ${ }^{11}$ At higher levels of aggregation there are independent effects of income inequality, whereas at lower levels of aggregation income inequality is mediated by neighbourhood consequences of income inequality and individual process. ${ }^{11}$ Our level of aggregation was low, but it was higher than the local area level used in the study by Soobader and LeClere, which showed an independent effect of income inequality on

Table 3 Hazard rate ratio estimates ( $95 \%$ confidence intervals) of all cause mortality in women (3460 deaths) and men (4109 deaths). Results from Cox's proportional hazards analysis, with age as underlying time scale

\begin{tabular}{|c|c|c|c|c|c|c|}
\hline & \multicolumn{2}{|c|}{ One variable in model } & \multicolumn{2}{|c|}{ Two variables in model } & \multicolumn{2}{|c|}{ All variables in model* } \\
\hline & Women & Men & Women & Men & Women & Men \\
\hline \multicolumn{7}{|l|}{ Area level } \\
\hline \multicolumn{7}{|l|}{ Income inequality: } \\
\hline $\begin{array}{l}\text { Lowest quarter } \\
\text { (least equality) }\end{array}$ & \multicolumn{2}{|c|}{1} & \multicolumn{2}{|c|}{1} & \multicolumn{2}{|c|}{1} \\
\hline Second quarter & 0.99 (0.84 to 1.18$)$ & $1.00(0.88$ to 1.13$)$ & $1.00(0.85$ to 1.16$)$ & $1.00(0.92$ to 1.10$)$ & $0.99(0.87$ to 1.12$)$ & $1.02(0.95$ to 1.10$)$ \\
\hline Third quarter & 0.96 (0.83 to 1.12$)$ & 0.92 (0.83 to 1.02$)$ & 0.98 (0.85 to 1.12$)$ & 0.95 (0.88 to 1.02$)$ & $1.04(0.92$ to 1.18$)$ & 1.00 (0.92 to 1.08$)$ \\
\hline $\begin{array}{l}\text { Highest quarter } \\
\text { (most equality) }\end{array}$ & 0.91 (0.78 to 1.05$)$ & 0.85 (0.76 to 0.96$)$ & 0.94 (0.82 to 1.08$)$ & 0.92 (0.84 to 1.01$)$ & $1.12(0.96$ to 1.30$)$ & 1.08 (0.95 to 1.22$)$ \\
\hline Test for linear trend & $P=0.52$ & $P=0.03$ & $P=0.78$ & $P=0.17$ & $P=0.46$ & $P=0.70$ \\
\hline \multicolumn{7}{|l|}{ Individual level } \\
\hline \multicolumn{7}{|l|}{ Household income: } \\
\hline Lowest quarter & 1 & & 1 & & 1 & \\
\hline Second quarter & 0.82 (0.77 to 0.88$)$ & $0.77(0.70$ to 0.85$)$ & $0.83(0.77$ to 0.88$)$ & $0.77(0.70$ to 0.85$)$ & 0.88 (0.82 to 0.94$)$ & $0.82(0.74$ to 0.91$)$ \\
\hline Third quarter & 0.77 (0.70 to 0.84$)$ & $0.62(0.56$ to 0.68$)$ & 0.77 (0.70 to 0.84$)$ & 0.63 (0.57 to 0.68$)$ & 0.86 (0.81 to 0.94$)$ & 0.73 (0.67 to 0.79$)$ \\
\hline Highest quarter & $0.60(0.54$ to 0.68$)$ & 0.51 (0.45 to 0.59$)$ & $0.61(0.54$ to 0.68$)$ & 0.52 (0.46 to 0.59$)$ & 0.68 (0.65 to 0.89$)$ & 0.64 (0.57 to 0.73$)$ \\
\hline Test for linear trend & $\mathrm{P}<0.01$ & $P<0.01$ & $P<0.01$ & $\mathrm{P}<0.01$ & $\mathrm{P}<0.01$ & $P<0.01$ \\
\hline
\end{tabular}

${ }^{*}$ Including factors in table and smoking status (non-smoker, smoker); physical activity (sedentary, active); body mass index (in four categories); average daily alcohol intake ( $<1$ drink (low), 1-2.9 drinks (moderate), and $\geqslant 3$ drinks (high)); household structure (in four categories); household income (in quarters); school education

( $<8$ years, 8-11 years and >11 years); and at area level, percentage of households with children (in tenths) and mean household income (in tenths)). 
self rated health. ${ }^{11}$ This supports the suggestion that the level of geographic aggregation needs further investigation. ${ }^{1}$

Three main interpretations have been proposed to explain the mechanisms behind the effects of income inequality on health: the individual income interpretation, the psychosocial environment interpretation, and the "neomaterial" interpretation. ${ }^{13}$ The latter comprises a combination of negative exposures and lack of resources by individuals, along with systematic under-investment across a wide range of societal infrastructures. Lynch et al stated that "an aggregate relation between income inequality and health is not necessary-associations are contingent on the level and distribution of other aspects of social resources." ${ }^{\prime 3}$ One explanation of our findings is that the Danish welfare system evens out the effects of many of the infrastructural components that are included in the complex mechanism linking area based inequality and health. For example, Danish housing policy ensures that even those relying on social welfare payments have access to housing in affluent as well as poorer areas. This contributes to greater economic variation in areas that would otherwise have had high average incomes and more equal income distributions. Consequently, we see what seem to be areas of high inequality of income that in fact have many features in common with high income areas-such as parks, playgrounds, and low crime rates. It is therefore debatable whether measures of such income inequality are adequate in the Nordic welfare states because income distribution is not linked to many other aspects of social infrastructure that are important for public health. The three main interpretations of the mechanisms at stake need further investigation; comparative studies would be valuable but should involve only countries that are comparable.

We thank John Lynch for valuable comments on the interpretation of the results.

Contributors: MO had the original idea for the study and wrote the paper. MO, EP, MG, and GE established the linkage of the dataset to Statistics Denmark. MO and EP did the data analyses. EP, MG, UC, PD, and GE commented on the earlier drafts and helped to interpret the findings. $\mathrm{MO}$ and $\mathrm{EP}$ are the guarantors.

Funding: Danish Heart Association and Danish Research Council.

Competing interests: None declared.

1 Kawachi I. Income inequality and health. In: Berkmann L, Kawachi I, eds. Social epidemiology. London: Oxford University Press, 2000.

2 Lynch J, Kaplan GA. Understanding how inequality in the distribution of income affects health. J Health Psychol 1997;2:297-314.

3 Wilkinson RG. Unhealthy societies: the affiction of inequality. London: Routledge, 1996.

4 Kaplan GA, Pamuk ER, Lynch JW, Cohen RD, Balfour JL. Inequality in income and mortality in the United States: analysis of mortality and potential pathways. BMJ 1996;312:999-1003.

5 Kennedy BP, Kawachi I, Prothrow-Stith D. Income distribution and mortality: cross-sectional ecological study of the Robin Hood index in the United States. BMJ 1996:312:1004-7.

6 Kawachi I, Kennedy BP, Lochner K, Prothrow-Stith D. Social capital, income inequality and mortality. Am J Public Health 1997;87:1491-8.

7 Wolfson M, Kaplan G, Lynch J, Ross N, Backlund E. Relation between income inequality and mortality: empirical demonstration. BMJ 1999;319:953-7
What is already known on this topic

Several ecological studies have shown that higher levels of income inequality in countries, states, or smaller areas are associated with higher all cause mortality

A few prospective studies from the United States have examined this after controlling for individual risk factors

\section{What this study adds}

Inequality in the distribution of income in parishes in Copenhagen is as high as inequality reported from metropolitan areas in the United States

Area based income inequality did not affect all cause mortality after adjustment for individual income and other risk factors

Denmark's welfare system (based on a Nordic model) may even out the effect of area inequality

8 Lynch JW, Kaplan GA, Pamuk ER, Cohen RD, Heck K, Balfour JL, et al. Income inequality and mortality in metropolitan areas of the United States. Am J Public Health 1998;88:1074-80.

9 Ross NA, Wolfson MC, Dunn JR, Berthelot J, Kaplan G, Lynch JW. Relation between income inequality and mortality in Canada and in the United States: cross sectional assessment using census data and vital statistics. BMJ 2000;320:898-902.

10 Diez-Roux AV, Link BG, Northridge ME. A multilevel analysis of income inequality and cardiovascular disease risk factors. Soc Sci Med 2000;50:673-87.

11 Soobader M, LeClere FB. Aggregation and the measurement of income inequality: effects on morbidity. Soc Sci Med 1999;48:733-44.

12 Kennedy BP, Kawachi I, Glass R, Prothrow-Stith D. Income distribution, socioeconomic status, and self rated health in the United States: multilevel analysis. BMJ 1998;317:917-21.

13 Lynch JW, Smith GD, Kaplan GA, House JS. Income inequality and mortality: importance to health of individual income, psychosocial environment, or material conditions. BMJ 2000;320:1002-4.

14 Fiscella K, Franks P. Poverty or income inequality as predictor of mortality: longitudinal cohort study. BMJ 1997;314:1724-8

15 Lochner K, Pamuk E, Makuc D, Kennedy BP, Kawachi I. State-level inequality and individual mortality risk: a prospective study. Am J Public Health 2001;91:385-91.

16 Daly MC, Duncan GJ, Kaplan GA, Lynch JW. Macro-to-micro links in the relation between income inequality and mortality. Milbank $Q$ 1998;76:315-39.

17 Waitzman NJ, Smith KR. Separate but lethal: the effect of economic segregation on mortality in metropolitan America. Milbank Q 1998;76:34173.

18 Appleyard M, Hansen AT, Schnohr P, Jensen G, Nyboe J. The Copenhagen city heart study. A book of tables with data from the first examination (1976-78) and 5-year follow-up (1981-83). Scand J Soc Med 1989;170:1160

19 Hagerup L, Schroll M, Hollnagel H, Agner E, Larsen S. The Glostrup population study. Collection of epidemiological tables. Reference values for use in cardiovascular population studies. Scand J Soc Med 1981;9(suppl 20):5-112.

20 Poulsen ME. Statistics on persons in Denmark. A register-based statistical system. Luxembourg: Eurostat, 1995.

21 United Nations. Provisional guidelines on statistics of the distribution of income, consumption and accumulation of households. UN: New York, 1977. (Statistical papers. Series M, No 61.)

22 Calyton D, Hill M. Statistical models in epidemiology. Oxford: Oxford University Press, 1993:302.

23 Grambsch PM, Therneau TM. Proportional hazard tests and diagnostics based on weighted residuals. Biometrika 1994;81:515-26.

24 Rogers WH. Regression standard errors in clustered samples. Stata Technical Bull 1993;13:19-23.

(Accepted 4 June 2001) 